\title{
Classification of Reinforcement Costs of Masonry Walls Using Hybrid \\ Extreme Gradient Boosting and Softmax
}

DOI : 10.36909/jer.13747

\author{
Melda Alkan Çakıroğlu ${ }^{1}$, Ahmet Ali Süzen²* \\ ${ }^{1}$ Department of Civil Engineering, Isparta University of Applied Sciences, 32200 Isparta, Turkey \\ ORCID: 0000-0002-8919-6278, E-mail: meldacakiroglu@isparta.edu.tr \\ ${ }^{2}$ Department of Information Security Technology , Isparta University of Applied Sciences, Isparta 32200, \\ Turkey ORCID: 0000-0002-5871-1652, E-mail:ahmetsuzen@isparta.edu.tr
}

\begin{abstract}
It has been built for centuries as housing and animal shelters, especially in rural areas, due to the advantages of masonry buildings being economical, being built with local materials, and not requiring skilled labor. The walls, which are the bearing elements of masonry structures, are formed by placing stones, bricks, or blocks on top of each other with a binding mortar. In this study, a model with the XGBoost algorithm, which is a tree-based classification algorithm, is proposed to scale cost of the samples reinforced with welded wire reinforcement/polypropylene fiber added dry mix shotcrete. The model executes cost classification based on concrete, steel mesh, steel, epoxy, fiber and workmanship independent parameters. A softmax function was incorporated into the model for classification. A complexity matrix was produced to evaluate classification performance of model. Also, it was compared to other machine learning algorithms. The model yielded higher accuracy and lower false-positive rates. As a result, the proposed model can make better estimates in cost classification compared to other machine learning methods. In conclusion, using the classification ability of the model, it is aimed to measure the cost effect in the construction process that calls for high labor force, time and cost.
\end{abstract}

Keywords: Dry mix shotcrete, masonry wall, cost estimate, construction costs, cost classification ensemble learning, XGBoosting 


\section{INTRODUCTION}

Masonry walls, which are among the oldest construction systems of the world, comprise a major part of existing building stock (Kariou et al., 2018; Padalu et al., 2018; Shrestha et al., 2020). The reasons for preference for masonry structures can be said to include being economical, easy to maintain, having attributes such as thermal insulation, fire protection and being made of local materials requiring simple construction technology (Shrestha et al., 2020). Such structures are usually built randomly without considering standards or making comprehensive research (Göker and Karaşin, 2015; Drougkas et al., 2019).

The strength of the masonry structure depends on the strength of the blocks forming the wall and of the binders, i.e. the strength of the wall (Göker and Karaşin, 2015; Bayülke, 2011). Despite recent advances in materials and applications, wall building techniques are the same as those developed about a thousand years ago (Lourenço, 1996). Putting each piece of brick or stone on top of each other with mortar is a simple but adequate technique (Lourenço, 1996; Ahmed et al., 2018). Since brick walls are the carrier of masonry structures, reinforcement should be performed without damaging the existing structure. Many different methods have been used to strengthen the walls till the present day (Kaçın and Güneş, 2020). Load- bearing masonry walls can be reinforced with simple materials such as steel mesh, repair mortar or shotcrete etc. In this application to be performed on one or both sides, additional shear force capacity can be brought to the wall by both repairing and thickening the wall (Celep, 2017).

Today, the rapid advances in data processing techniques and the emergence of different artificial intelligence approaches have led to the development of different applications for masonry walls. In view of the artificial intelligence studies in the literature, ensemble learning methods in machine learning algorithms have been highly recommended in recent years (Liu et al., 2020; Qian et al., 2020; Wang et al., 2019a; Wang et al., 2019b; Nguyen et al., 2020). Ensemble learning goes beyond the generalization of a single machine learning algorithm, foreseeing an approach to combine different algorithms. The classification and prediction performance of the network can be maximized if the optimum parameters for the neural network are selected in ensemble algorithms. Bagging, Boosting, AdaBoost, and Stacked Generalization methods are widely used in ensemble learning. 
In this study, a new hybrid approach was presented with XGBoost ensemble learning algorithm to scale and classify the effects of various reinforcement techniques of masonry walls (mesh steel and dry mix shotcrete with added polypropylene fiber) on costs (transport, storage, workmanship). The proposed model classifies the elements affecting cost (concrete, mesh steel, iron, epoxy, fiber, mesh steel and anchorage work, shotcrete work) according to 5 different types of cost. In terms of cost, accuracy and validity, the suitability of the proposed method stands out. The dataset used for the training of the model was obtained after experimental studies. Optimum hyper parameters for training and testing of the model were determined. Following training and testing of the model, it was compared with other machine learning algorithms to evaluate its performance. In line with the comparison results, the highest accuracy was obtained for the proposed XGBoosting-based model with an accuracy of $90.80 \%$.

\section{RELATED WORK}

Cost estimates significantly affect planning, design, bidding, cost management/budgeting and construction management. Such estimates allow the property owners assess project possibility and the project owners and planners to assess project feasibility at detailed project design stage and control costs effectively (Cheng et al., 2009 ; Khalaf et al., 2020). Cost estimation of projects in the construction industry has always been difficult due to the fact that works are often carried out in an uncertain environment (Cheng et al., 2013). Construction costs depend on fluctuations tending to increase in the long run, which makes the pricing process challenging (Elfahham, 2019). Due to resource planning, risk management and logistic difficulties in the construction industry, delays in project delivery, cost overruns and contract disputes might often occur. In order to prevent these, studies on the application of advanced machine learning algorithms such as deep learning have been encouraged. Especially in the construction sector, there are many deep learning applications that have not yet been discovered in areas such as site planning and management, health and safety and construction cost estimation (Akinosho, 2020).

Traditionally, cost estimation models have been developed using statistical methods. Regression analysis is a traditional alternative that has the disadvantage of requiring a defined mathematical form for cost functions. In addition, traditional methods prevent accurately estimating project costs due to the large number of important variables and their interactions. Therefore, the applicability of traditional methods is limited. Artificial 
intelligence approaches, Case-Based Reasoning (CBR), Neural Networks (NNs), Fuzzy Logic (FL), Genetic Algorithms (GAs) and their derivatives can be applied to cost estimation problems (Cheng et al., 2009).

Studies seems to have been done reflect the out-of-plane and in-plane behavior and damage status of the masonry wall when the literature studies (Shawa et al., 2012; Varela, 2011; Maheri and Najafgholipour, 2012; Sorrentino et al., 2016; Malomo et al., 2020; Bagheri el al., 2020) were examined. Also to examine the distribution of sprayed concrete fibre, fiber, image processing and machine learning (Manca et al., 2018), to identify the variations in masonry the crack in the wall digital image correlation (DIC) technique (Tung et al., 2008), the behavior of masonry walls of a simple micro-simulation model (Abdulla et al., 2017), for the prediction of compressive strength of masonry prisms artificial neural network (ANN) models of the application (Asteris et al., 2018) SVR and back-propagation artificial neural network: a comparison of methods to predict 28-day strength of shotcrete (Kalhori and Bagherpour, 2019), the implementation of ANN method for predicting the shear strength of FRM masonry (Cascardi et al., 2016), the failure loads of masonry walls is estimated using the ANN method ( Demir and Kumanlıoğlu, 2017), for the prediction of the axial behaviour of brick masonry walls, the use of ANNs (Garzón-Roca et al., 2013), structural damage detection based deep learning model for the ANN (Pathirage et al., 2018), neural network using neural network to estimate the relationship between the rheological properties of mortar and shotcrete material parameters (Phan et al., 2002), using machine learning, automatic detection and classification of stone masonry of defects (Valero et al., 2018;Valero et al., 2019), artificial neural networks for prediction of the cost of masonry houses (Uğur et al., 2011), calculating the approximate cost of the building with BIM (Karagöz, 2019), the effect of masonry building strengthening on structural safety and cost (Akçay and Yıldızlar, 2019), the possibility of occurrence of the risk factors and their effects on the cost (Al-Sabah and Refaat, 2019), the impact of the oil price changes on Kuwait's construction industry (Al-Tabtabai and Soliman, 2021), calculating the approximate cost of shotcrete (Çakıroğlu and Süzen, 2020) are some of the studies in the literature.

It can be seen that the researchers developed various methods / models in order to estimate the cost with the highest level of accuracy by evaluating the limited data available in their studies. In addition, this study, which offers a new hybrid approach with the XGBoost ensemble learning algorithm, is thought to contribute to the literature by bringing a different perspective, given the limited number of studies on the cost of reinforcing masonry structures in the literature.

We can explain the innovations and contributions of our proposed study as follows. 
- Cost classification from masonry wall data

- A novel method for classification with extreme gradient boosting and softmax

- A unique dataset for cost classification

\section{EXPERIMENTAL METHOD}

\subsection{Experimental Study for Dataset}

In this study, the costs of reinforced masonry walls within the scope of TÜBİTAK 1001 project (Tübitak, 2013) were used as data in the modeling performed to scale and classify the effects of reinforcement techniques (mesh steel, polypropylene fiber reinforced dry-mix shotcrete) on costs (transport, storage, workmanship).

For the experimental study, $220 \times 245 \mathrm{~cm}$ brick wall samples were put up in the form of checker brick work using $19 \mathrm{~cm} \times 9 \mathrm{~cm} \times 5 \mathrm{~cm}$ solid clay bricks with $1 \mathrm{~cm}$ joint spacing. A total of 14 brick wall samples were prepared by creating 7 series, including 2 samples in each series. A rough cast with an average thickness of $20 \mathrm{~mm}$ was applied on the front and back surfaces of the wall samples, and a finish plaster with an average thickness of 8 mm was applied on the rough cast. In Figure. 1, a general view of the brick wall samples which were put up and plastered is given. The codes assigned to the samples in each series under the study are given in Table 1.
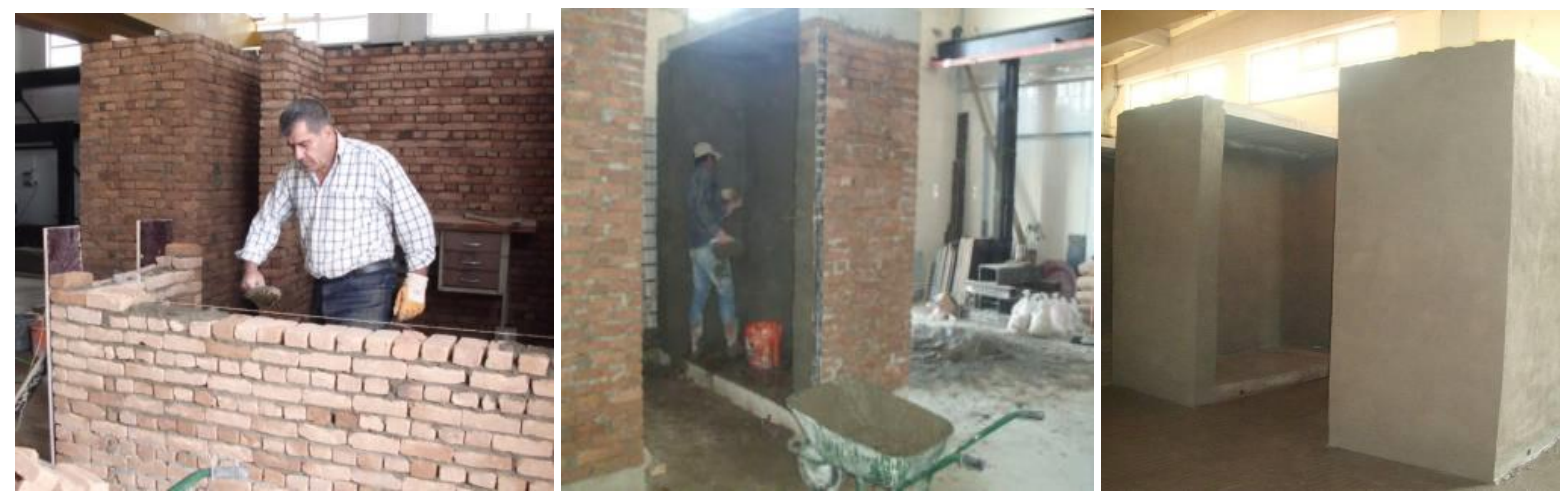

Figure 1. Brick wall samples

Table 1. Samples in the series

\begin{tabular}{|c|c|c|c|}
\hline Sample Type & Piece & Reinforcement Technique & Shotcrete Thickness (mm) \\
\hline Plain & 1 & - & - \\
\hline Steel Mesh & 1 & Q188/188 steel mesh & 50 \\
\hline Steel Mesh & 1 & Q188/188 steel mesh & 100 \\
\hline Polypropylene Fiber & 1 & $\begin{array}{c}5 \mathrm{~kg} / \mathrm{m}^{3} \text { Polypropylene fiber }+2 \mathrm{~kg} / \mathrm{m}^{3} \\
\text { spray fiber }\end{array}$ & 50 \\
\hline Polypropylene Fiber & 1 & $\begin{array}{c}5 \mathrm{~kg} / \mathrm{m}^{3} \text { Polypropylene fiber }+2 \mathrm{~kg} / \mathrm{m}^{3} \\
\text { spray fiber }\end{array}$ & 100 \\
\hline Polypropylene Fiber & 1 & $\begin{array}{c}9 \mathrm{~kg} / \mathrm{m}^{3} \text { Polypropylene fiber }+2 \mathrm{~kg} / \mathrm{m}^{3} \\
\text { spray fiber }\end{array}$ & 50 \\
\hline
\end{tabular}


The first series of brick wall samples was produced as plain, dry mix shotcrete was applied to the front surfaces of brick wall samples by placing Q188/188 type steel mesh in the second and third series, by adding $5 \mathrm{~kg} / \mathrm{m}^{3}$ of polypropylene fiber and $2 \mathrm{~kg} / \mathrm{m}^{3}$ of spray fiber in fourth and fifth series and by adding $9 \mathrm{~kg} / \mathrm{m}^{3}$ of polypropylene fiber and $2 \mathrm{~kg} / \mathrm{m}^{3}$ of spray fiber in sixth and seventh series.

Anchorage rods were placed on the wall surface in order to be able to mount mesh reinforcements to the wall samples. Two-component epoxy material was used to fix the anchor rods. After the anchorage application, steel mesh reinforcements were placed in the wall sample. Dry mix shotcrete layer thickness applied to each series was determined as $50 \mathrm{~mm}$ and $100 \mathrm{~mm}$. The polypropylene fiber was macro/mono filament fiber. In dry mix shotcrete application, the largest aggregate grain size was selected as $8 \mathrm{~mm}$, and cement dose was selected as $500 \mathrm{~kg} / \mathrm{m}^{3}$. The w/c ratio was set by the operator at the tip of the hose. CEM II 42.5 cement was used in the application. As an admixture, a setting accelerator powder concrete admixture at a ratio of $5.5 \%$ of the total binder dose was used. The water used was potable mains water (Tübitak, 2013).

\subsection{Preparation of the Dataset}

The dataset to be used in the training and testing of the model has been prepared with the first step. In the first step, the determination and labeling of the variable were carried out, and in the second step, the normalization of the data was carried out.

The experimental study of brick masonry walls and dry mix sprayed concrete the addition of polypropylene fiber reinforcing with steel mesh, the cost of the main groups (materials, shipping, storage, and Labor) (Figure 2) and sub-group (shotcrete, epoxy, polypropylene fiber, steel wire mesh, wire mesh, a steel worker, anchors, masonry, concrete spraying crafting) has been classified on. In the study, a classification scale was used to provide information about the variable. In order to determine the options of quantitative data, the number of main group classes was determined as $3(0,1$, and 2$)$ and, accordingly, the evaluation range (0-none, 1-less, and 2-more). The number of subgroup classes was treated as 5 and the evaluation range (1-None, 2-very low, 3-low, 4-high, and 5-Very High). 
All data is included in the classification. After defining classes, it is determined which class each value will enter. The boundaries of the classes created are set as maximum and minimum values. The range of changes $(R)$ defined as the difference between the minimum and maximum value contained in the main mass or sample was calculated by subtracting the minimum values from the maximum values of the cost expenses recorded in the experimental study according to Equation 1 (Çetintaş and Nazlı, 2018; Akın,2017). By dividing the change range value by the number of classes, the Class range is obtained (Equation 2) (Akın,2017).

$R=X \max -X \min$

Class Range $=\frac{R}{\text { Number of Classes }}$

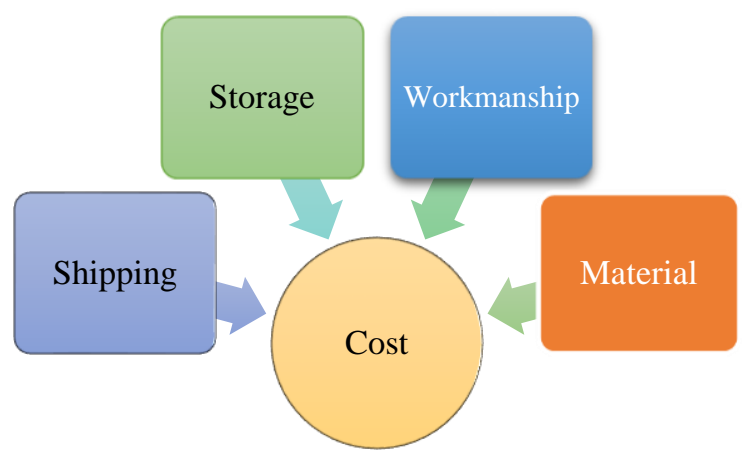

Figure 2. Cost components parameters

Data from the experimental study was linearly normalized for training and testing of the model. Min-max scaling is used for this. In the Min-max scale, the maximum value of each argument is defined as $\mathrm{x}_{\max }$, and the minimum value is defined as $\mathrm{X}_{\min }$. $\mathrm{X}^{\prime}$ normalized data is calculated against each $\mathrm{X}_{\mathrm{i}}$ input value. Independent and dependent variables determined for the training of the model and its parametric value in the model are given in Table 2.

Table 2. Independent and dependent variables of the model

\begin{tabular}{ll}
\hline Parameters & Explanation \\
\hline btn_value & Concrete $\mathrm{m} 2$ price \\
hc_value & Wicker Grasshopper $\mathrm{m} 2$ price \\
$\mathrm{dmr}$ _ value & Iron kg price \\
ep_value & Epoxy PCS price \\
lif_value & Fiber $\mathrm{m} 2$ price \\
$\mathrm{n} \_$value & Shipping $\mathrm{m} 2$ price \\
ha_value & Wicker and anchor craftsmanship $\mathrm{m} 2$ price \\
li_value & Fiber crafting kg price \\
pb_value & Shotcrete workmanship $\mathrm{m} 2$ price \\
sonu_value & Cost classification value \\
\hline
\end{tabular}




\section{PROPOSED MODEL}

In the study, XGBoosting, one of the ensemble learning algorithms used for cost classification, consists of a series of classification and regression trees based on the decision tree (Liu et al., 2020). At the same time, XGBoosting is a Gradient boosting algorithm optimized for high efficiency (Wang et al., 2019b). The proposed model was developed using the Keras library with Spyder software. The Model has 9 different input parameters, with each input represented as $\mathrm{x}_{\mathrm{i}}$. The target classification parameter is stored in variable $\mathrm{y}_{\mathrm{y}} \mathrm{y}_{\mathrm{i}}$, the classification estimate for an $\mathrm{x}_{\mathrm{i}}$ entry entered in the model, is shown as in Equation 3.

$y_{i}=\sum_{n=1}^{N} f_{n}\left(x_{i}\right), f_{n} \in F$

Where, $\mathrm{N}$ represents the total tree iteration. In each tree structure, the loss function $\mathrm{L}(\theta)$ is used to minimize errors of the value of the objective function $\operatorname{obj}(\theta)$. In this way, a fair value can be obtained with each addition of new trees. An editing function called $\Omega(\theta)$ is added to the xgboosting algorithm to prevent overeducation by increasing the amount of trees in this branching. the definition of the objective function obj $(\theta)$ is as in Equation 4.

$$
\begin{aligned}
& \operatorname{obj}(\theta)=L(\theta)+\Omega(\theta) \\
& =\sum_{i}^{n} l\left(y_{i}, \hat{y}_{i}\right)+\sum_{n=1}^{N} \Omega\left(f_{k}\right)
\end{aligned}
$$

The basic tree structure needs to be adapted in multiple classifications because it supports binary classification in the tree structure based on XGBoosting. In this context, purpose and gain functions should be valued from all classes. For this, it calculates the average loss of the model over all targets. The gain in the trees of the model corresponds to the sum of Equation 5.

GainSum $=\sum_{j=1}^{N}\left(\frac{G_{J}^{2}}{h_{j}+\lambda}\right)$

As can be seen in Equation 6 in improving the model, $H_{v}$ is the weight of each sample, $G_{v}$ is the gradient sum of all IV samples in each branch. Also, $\mathrm{w}_{\mathrm{v}}$ is the weight vector of each branch score. In the classification, the value of $\mathrm{j}$ is extended to $1 \leq \mathrm{j} \leq 5$.

$G_{j, v}=\sum_{i \in I_{v}} g_{i, i}, H_{i, v}=\sum_{i \in I_{v}} h_{i, i}, W_{v}=-\frac{G_{v}}{H_{v}+\omega}$ 
For multiple classification of the output of the model, Softmax Regression was used as $y(I)=\leq\{1,2,3,4,5\}: n=5$. Where $\mathrm{N}$ is the total number of classes. The Softmax function consists of input, classifier, and output units.

Parameter optimization is an important factor to achieve the best result when training the XGBoosting model shown in Figure. 3. For this reason, GridSearchCV was used to determine optimal parameters. GridSearchCV returns the hyperparameter set that gives the best score by applying the hyperparameter combinations to the model one by one and checking the score in each model (Ranjan et al., 2019). In order to get the highest efficiency and accuracy from the model, the optimal hyperparameters originally determined in the dataset are given in Table 3. Due to the determined hyperparameters, the predictive power of the model has been increased and the learning time has been optimized.

Table 3. Parameters and optimum values of the XGBoosting model

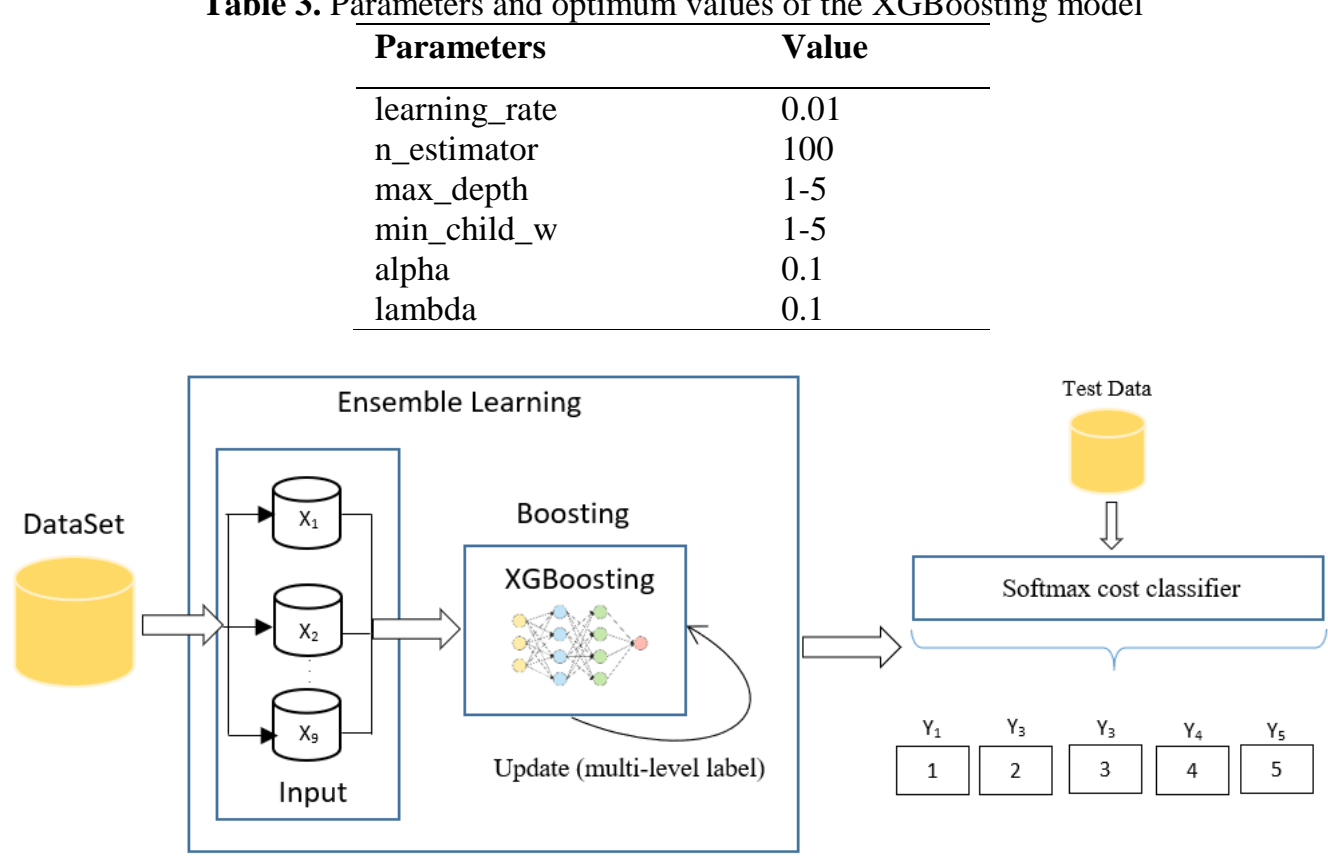

Figure 3. Architecture of development of the proposed classification model

\section{RESULTS}

\subsection{Evaluation Metrics}

Accuracy (acc) (Equation 7), recall (Equation 8), and precision (Equation 9) metrics were preferred to evaluate the classification success of the proposed xgboosting and Sofmax model. The parametric values in Acc, recall, and precision are described as follows (Süzen, 2020). 
- True positive (TP): The true result is given for the true cost classification.

- $\quad$ False Positive (FP): The false result is given for the true cost classification.

- $\quad$ False Negative (FN): The false result is given for the false cost classification.

- True Negative (TN): The true result is given for the false cost classification.

$A c c=\frac{T P+T N}{T P+T N+F P+F N}$

recall $=\frac{T P}{T P+F N}$

precision $=\frac{T P}{T P+F P}$

\subsection{Evaluation of Model}

The training and testing process of the developed model was carried out on the i9 $3.60 \mathrm{GHz} 12-\mathrm{Core}$ CPU, 64GB of RAM, and an NVIDIA 11 GB RTX 2080 TI-enabled artificial intelligence computer. The Model rates the cost classification from 1 to 5 according to 9 different independent input parameters. According to the input parameters obtained, the output classification is performed by the softmax function. Figure 4 shows the confusion matrix for the classification of the model. The confusion matrix shows the number of classifications estimated by the model and its accuracy rate according to 5 different cost scales. In the false classifications that the model produces against the correct classification, it seems that the parametric independent input values are close to each other. This shows that the input parameters contained in the dataset are not the desired number. But the classification success of the model is maximum thanks to hyperparameters that are improved with an average accuracy of $90.80 \%$. It is assumed that expanding the dataset will reduce the ratio of false positives and false negatives in the classification of the model. 


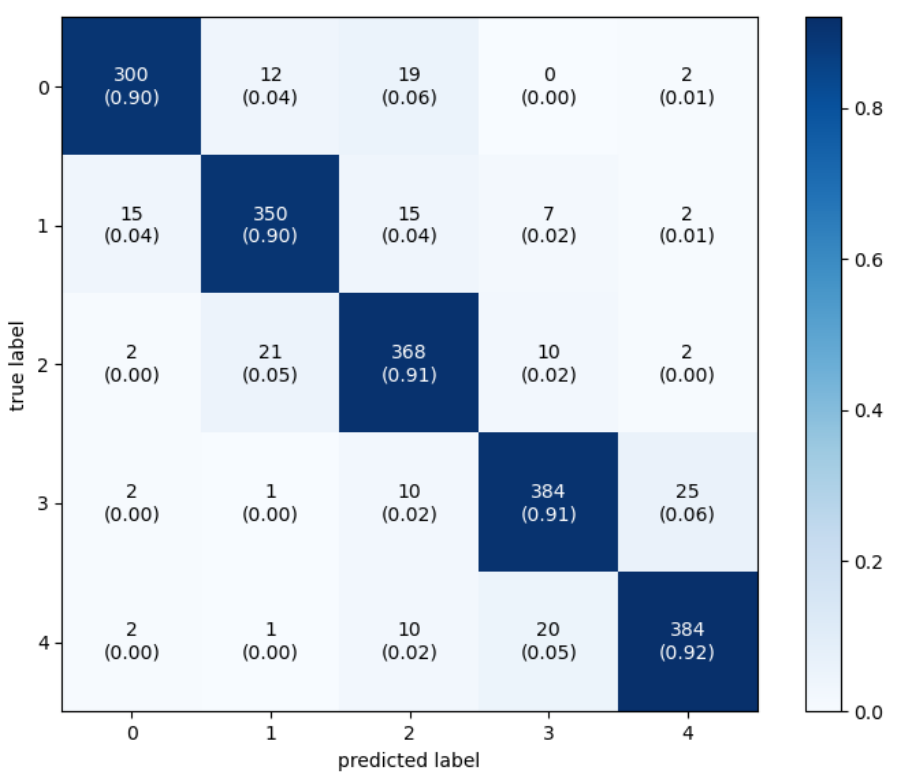

Figure 4 .Confusion matrix of the classification model

In order to evaluate the success of the developed model in cost classification, was compared with SVM classifier, Random Forest, and Naive Bayes machine learning algorithms. According to the comparison results given in Table 4, the proposed model achieved the highest accuracy value compared to the others. Although the proposed XGBoosting model tree structure was capable of binary classification, the change in a tree structure and the addition of the softmax multiple classifications also demonstrated the model's success in multiple classifications.

Table 4. Comparison of the proposed model with other machine learning algorithms

\begin{tabular}{lllc}
\hline Model & Acc $(\%)$ & recall & precision \\
\hline XGBoosting and Softmax Model & 90.80 & 0.84 & 0.87 \\
SVM classifier & 87.25 & 0.81 & 0.83 \\
Random Forest & 83.10 & 0.77 & 0.78 \\
Naive Bayes & 81.50 & 0.65 & 0.72 \\
\hline
\end{tabular}

\section{CONCLUSIONS}

In the construction sector, which is considered one of the most important sectors in terms of its impact on the economy and employment, planning and supervision of each stage of the construction process in terms of cost is of great importance. For this reason, it is important to base the cost of masonry structures on a comprehensive and realistic cost estimate prepared based on new approaches so that the impact of various parameters on the cost 
in the construction process of the structure can be measured. In this context, a hybrid neural network model that classifies costs according to input parameters has been proposed. The Model can classify according to 5 different cost scales with xgboosting and Softmax architectures. Optimum parameters were determined using GridSearchCV for high accuracy and stability of the model. As a result, in the proposed model cost classification, it was found to work better than other machine learning methods with an accuracy of $90.80 \%$.

The difficulty of construction work causes the dataset to be scarce. For this reason, it is envisaged that by expanding the dataset in future studies, the accuracy obtained will be increased. In addition, after providing sufficient data, it is planned to redevelop the model with deep learning algorithms, ensuring higher classification success.

\section{Compliance with ethical standards}

\section{Conflict of Interest}

The authors declare that they have no conflict of interest.

\section{Acknowledgments}

In this study, the data obtained from the costs of the brick wall samples produced within the scope of the TÜBİTAK 1001111 M335 project titled "Reinforcement of Out-of-Plane Loaded Masonry Constructions with Polypropylene Fiber Reinforced Dry-Mix Shotcrete" was used in modelling with the XGBoost algorithm. Teherefore, we would like to thank TÜBİTAK.

\section{References}

Abdulla, K.F., Cunningham, L.S., Gillie, M., 2017. Simulating Masonry Wall Behaviour Using a Simplified Micro-Model Approach, $\quad$ Engineering $\quad$ Structures $349-365$. http://dx.doi.org/10.1016/j.engstruct.2017.08.021

Ahmed, A., Ahmad, I., Shahzada, K., Naqash, M.T., Alam, B., Fahad, M., Khan, S.W., 2018. Seismic Capacity Assessment of Confined Brick Masonry Building: An Experimental Approach, Hindawi Shock and Vibration, Volume 2018, Article ID 4756352, 10 pages. https://doi.org/10.1155/2018/4756352 
Akçay, C., \& Yıldızlar, B., 2019. Assessment in Terms of Cost and Structural Safety of Strengthening in Masonry Structures, Journal of Engineering Sciences and Design, 7(1), 34-39. DOI:10.21923/jesd.414102

Akın, H.B., 2017. Use of Computer Programs Implementation of Qualiy Control Techniques. İstanbul Aydın University Journal of Anadolu Bil Vocational School of Higher Education, 47, 1- 19.

Akinosho, T.D., Oyedele, O.L., Bilal, M., Ajayi, A.O., Delgado, M.D., Akinade, O.O., Ahmed, A.A.,2020. Deep Learning in the Construction Industry: A Review of Present Status and Future Innovations. Journal of Building Engineering, https://doi.org/10.1016/j.jobe.2020.101827

Al-Sabah, R., and Refaat, O., 2019. Assessment of Construction Risks in Public Projects Located in the State of Kuwait. Journal of Engg. Research Vol. 7 No. (3) September 2019 pp. 13-32

Al-Tabtabai, H., and Soliman, E., 2021. Oil Prices Drop Effect on Construction Industry in Kuwait. Journal of Engg. Research Online First Article. DOI : 10.36909/jer.13377.

Asteris, P.G., Argyropoulos, J., Cavaleri, L., Rodrigues, H., Varum, H., Thomas, J., Lourenço, P.B., 2018. Masonry Compressive Strength Prediction using Artificial Neural Networks, 1st International Conference TMM_CH Transdisciplinary Multispectral Modelling and Cooperation for the Preservation of Cultural Heritage, Athens, Greece, 10-13.

Bagheri, B., Lee, J-H., Kim, H-G., Oh, S-H.,2020. Experimental Evaluation of the Seismic Performance of Retrofitted Masonry Walls, Composite Structures. https://doi.org/10.1016/j.compstruct.2020.111997

Bayülke, N., 2011. Earthquake Behavior and Safety of Masonry Structures, 1st Turkish Conference on Earthquake Engineering and Seismology, ODTÜ - Ankara, 11-14.

Çakıroğlu, A., M., Süzen, A. A., Marangoz, İ., 2020. Developing an Application for Approximate Cost Analysis of Shotcrete, Journal of Engineering Sciences and Design, 8(1), 153-164. Doi: 10.21923/jesd.562008.

Cascardi A., Micelli F., Aiello M.A., 2016 .Analytical Model Based on Artificial Neural Network for Masonry Shear Walls Strengthened with FRM Systems, Composites Part B, http://dx 10.1016/j.compositesb.2016.03.066.

Celep, Z., 2017. Introduction to Earthquake Engineering and Earthquake Resistant Building Design. Fifth edition, Beta edition release distribution.

Çetintaş, S., \& Nazlı, İ., 2018. Investigation of Thickness and Brightness Change with Shewhart Control Charts in Natural Stone Polishing Process, Scientific Mining Journal, 57(3), 177-187. 
Cheng, M-Y, Hoang, N-D, Wu,Y-W., 2013. Hybrid Intelligence Approach Based on LS-SVM and Differential Evolution for Construction Cost Index Estimation: A Taiwan Case Study, Automation in Construction, http://dx.doi.org/10.1016/j.autcon.2013.05.018

Cheng, M-Y., Tsai, H-C., Hsieh, W-S., 2009. Web-Based Conceptual Cost Estimates for Construction Projects Using Evolutionary Fuzzy Neural Inference Model, Automation in Construction 18, 164-172, doi:10.1016/j.autcon.2008.07.001

Demir, A., \& Kumanlığlu, A.A., 2017. The Prediction of Brick Wall Strengths with Artificial Neural Networks Model, AIP Conference Proceedings 1798, 020045. doi: 10.1063/1.4972637

Drougkas, A., Roca, P., Molins, C., 2019. Experimental Analysis and Detailed Micro-Modeling of Masonry Walls Subjected to In-Plane Shear, Engineering Failure Analysis 95, 82-95. https://doi.org/10.1016/j.engfailanal.2018.08.030

Elfahham, Y., 2019. Estimation and Prediction of Construction Cost Index using Neural Networks, Time Series, and Regression, Alexandria Engineering Journal, 58, 499-506. https://doi.org/10.1016/j.aej.2019.05.002

Garzón-Roca, J., Adam, J.M., Sandoval, C., Roca, P., Estimation of the Axial Behaviour of Masonry Walls Based on Artificial Neural Networks, Computers and Structures 125, 145-152, 2013. http://dx.doi.org/10.1016/j.compstruc.2013.05.006

Göker, Ş., \& Karaşin, A., 2015. A Structural Damage Assessment for Rural Structures Damaged by an Earthquake, Dicle University Journal of $\quad$ Engineering, 1(6), 31-38. https://doi.org/10.1016/j.soildyn.2020.106056

Kaçın, S., \& Güneş, E., 2020. Plastic Composite Equipment Using in Strengthening Walls. Nigde Omer Halisdemir University Journal of Engineering Sciences, 9(2), 946-955.

Kalhori, H., \& Bagherpour, R.,2019. Prediction of Shotcrete Compressive Strength Using Intelligent Methods; Neural Network and Support Vector Regression, CWB-2/2019, 126-136.

Karagöz, E.M., 2019. Proposal Building Approximate Cost Calculation with BIM, Building Information Modeling, 1(1), 39-45.

Kariou, F.A., Triantafyllou, S.P., Bournas, D.A., Koutas, L.N., 2018. Out-of-Plane Response of Masonry Walls Strengthened Using Textile-Mortar System, Construction and Building Materials 165, 769-781. https://doi.org/10.1016/j.conbuildmat.2018.01.026 
Khalaf, T.Z., 2020. Hybrid PSO-ANN and PSO Models Based Approach for Estimationa of Costs and Duration of Construction Projects, MSc. Thesis, Kastamonu University Graduate School of Natural and Applied Sciences, Department of Engineering Management.

Liu, K., Chen,\& W., Lin, H.,2020. XG-PseU: an eXtreme Gradient Boosting based method for identifying pseudouridine sites. Molecular Genetics and Genomics, 295(1), 13-21.

Lourenço, P.J.B.B., 1996. Computational Strategies for Masonry Structures, Delft University Press Stevinweg 12628 CN Delft The Netherlands.

Maheri, M.R., \& Najafgholipour, M.A.,2012. In-Plane Shear and Out-of-Plane Bending Capacity Interaction in Brick Masonry Walls, 15 WCEE Lisboa.

Malomo, D., Pinhoa, R., Penna, A., 2020. Numerical Modelling of the Out-of-Plane Response of Full-Scale Brick Masonry Prototypes Subjected to Incremental Dynamic Shake-Table Tests, Engineering Structures 209, 110298. https://doi.org/10.1016/j.engstruct.2020.110298

Manca, M., Karrech, A., Dight, P., Ciancio, D., 2018. Image Processing and Machine Learning to Investigate Fibre Distribution on Fibre-Reinforced Shotcrete Round Determinate Panels, Construction and Building Materials 190, 870-880. https://doi.org/10.1016/j.conbuildmat.2018.09.141

Nguyen, P. T., Ha, D. H., Jaafari, A., Nguyen, H. D., Van Phong, T., Al-Ansari, N., Pham, B. T., 2020. Groundwater Potential Mapping Combining Artificial Neural Network and Real AdaBoost Ensemble Technique: The DakNong Province Case-study, Vietnam. International Journal of Environmental Research and Public Health, 17(7), 2473.

Padalu, P.K.V.R., Singh, Y., Das, S., 2018. Experimental Investigation of Out-of-Plane Behaviour of URM Wallettes Strengthened Using Welded Wire Mesh, Construction and Building Materials 190, 1133-1153. https://doi.org/10.1016/j.conbuildmat.2018.09.176

Pathirage, C.S.N., Li, J., Li, L., Hao, H., Liu, W., Ni, P., 2018. Structural Damage Identification Based on Autoencoder Neural Networks and Deep Learning, Engineering Structures 172, 13-28. https://doi.org/10.1016/j.engstruct.2018.05.109

Phan, Q.H.D., Baba, K., Uomoto, T., 2002. Prediction of Rheological Properties of Mortar for Shotcrete Using Neural Network, (24)1. https://pdfs.semanticscholar.org/71db/ce545a4fec191fc3943f885306c0c533747a.pdf 
Qian, N., Wang, X., Fu, Y., Zhao, Z., Xu, J., Chen, J., 2020. Predicting Heat Transfer of Oscillating Heat Pipes for Machining Processes Based on Extreme Gradient Boosting Algorithm. Applied Thermal Engineering, 164, 114521

Ranjan, G. S. K., Verma, A. K., \& Radhika, S. 2019. K-nearest Neighbors and Grid Search CV Based Real Time Fault Monitoring System for Industries. In 2019 IEEE 5th international conference for convergence in technology (I2CT) (pp. 1-5). IEEE.

Shawa, O.A., de Felice, G., Mauro, A., Sorrentino, L., 2020. Out-of-Plane Seismic Behaviour of Rocking Masonry Walls, Earthquake Engineering and Structural Dynamics Earthquake Engng Struct. Dyn. 41, 949_968, 2012. DOI: 10.1002/eqe.1168,

Shrestha, J.K., Bhandari, S., Pradhan, S., Gautam, D., Simplified Frame Model for Capacity Assessment of Masonry Buildings, Soil Dynamics and Earthquake Engineering 131, 106056.

Sorrentino, L., D’Ayala, D., de Felice, G., Griffith, M.C., Lagomarsino, S., Magenes, G.,2016. Review Of Out-Of-Plane Seismic Assessment Techniques Applied To Existing Masonry Buildings, International Journal of Architectural Heritage. http://dx.doi.org/10.1080/15583058.2016.1237586

Süzen, A. A., 2020. Developing A Multi-Level Intrusion Detection System Using Hybrid-DBN. Journal of Ambient Intelligence and Humanized Computing, 12(2), 1913-1923. https://doi.org/10.1007/s12652-020$\underline{02271-\mathrm{W}}$

TÜBITTAK 111M335. Reinforcement of Masonry Constructions Which are Charged out-of Plane with Polypopylene Fibre Dry Mix Shotcrete, The Scientific and Technological Research Council of Turkey, TÜBİTAK 1001 Scientific and Technological Research Projects Support Program, Project Number: 111M335, Project Researchers: Çakıroğlu, A.M., Tekeli, H., and İnce, G., Isparta, 2013.

Tung, S-H., Shih, M-H., Sung, W-P.,2008. Development of Digital Image Correlation Method to Analyse Crack Variations of Masonry Wall, Sādhanā Vol. 33, Part 6, December 2008, 767-779.

Uğur, L.O., Baykan, U.N., Korkmaz, S., 2011. The Use of Artificial Neural Networks (ANN) in Cost Estimation of Masonry Houses, $6^{\text {th }}$ Construction Management Congress, 25-26-27 November, 2011, TMMOB Chamber of Civil Engineers, Bursa, 223-234.

Valero, E., Forster, A., Bosché, F., Hyslop, E., Wilson, L., Turmel, A.,2019. Automated Defect Detection and Classification in Ashlar Masonry Walls Using Machine Learning, Automation in Construction 106, 102846, https://doi.org/10.1016/j.autcon.2019.102846 
Valero, E., Forster, A., Bosché, F., Renier, C., Hyslop, E., Wilson, L.,2018. High Level-of-Detail BIM and Machine Learning for Automated Masonry Wall Defect Surveying, 35th International Symposium on Automation and Robotics in Construction (ISARC 2018).

Varela-Rivera, J.L., Navarrete-Macias, D., Fernandez-Baqueiro, L.E., Moreno, E.I.,2011. Out-of-Plane Behaviour of Confined Masonry Walls, Engineering Structures 33, 1734-1741.

Wang, F., Jiang, D., Wen, H., Song, H.,2019a. Adaboost-Based Security Level Classification of Mobile Intelligent Terminals. The Journal of Supercomputing, 75(11), 7460-7478.

Wang, F., Li, Z., He, F., Wang, R., Yu, W., \& Nie, F.,2019b. Feature Learning Viewpoint of AdaBoost and A New Algorithm. IEEE Access, 7, 149890-149899. 